\title{
AVALIAÇÃO DA QUALIDADE PROTÉICA DE UMA DIETA ESTABELECIDA EM QUISSAMÃ, RIO DE JANEIRO, ADICIONADA OU NÃO DE MULTIMISTURA E DE PÓ DE FOLHA DE MANDIOCA
}

\author{
PROTEIN QUALITY EVALUATION OF A DIET ESTABLISHED IN QUISSAMÃ, \\ RIO DE JANEIRO, BRAZIL, ADDED OR NOT WITH \\ MULTI-MIXTURE AND POWDER OF CASSAVA LEAF
}

\author{
Gilson Teles BOAVENTURA' \\ Claudete Corrêa de Jesus CHIAPPINI' \\ Núbia Regina ASSIS FERNANDES² \\ Elaine Martins de OLIVEIRA ${ }^{2}$
}

\begin{abstract}
RESUMO
O trabalho avaliou a qualidade protéica da dieta consumida por crianças desnutridas do município de Quissamã, Rio de Janeiro, e adicionada da multimistura ou do pó de folha de mandioca, utilizando 48 Rattus norvergicus, Wistar, machos, com 24 dias, pesando 58,95 g, recebendo água e ração ad libitum. Na primeira fase, denominada de Desnutrição, os animais foram distribuídos em grupo controle, alimentados com ração à base de caseína, grupo Quissamã alimentados com ração à base da dieta estabelecida em Quissamã, ambos com $n=8$ animais, e grupo aprotéico com $n=32$, recebendo uma dieta isenta de proteínas durante 10 dias. Na segunda fase, denominada de Recuperação, com duração de 18 dias, o grupo central e o grupo Quissamã permaneceram recebendo a mesma ração. O grupo aprotéico foi desmembrado em grupo desnutrido controle, alimentado com a mesma ração do grupo central e grupo desnutrido Quissamã, alimentado com a mesma ração do grupo Quissamã e mais dois grupos desnutridos recebendo a ração do grupo desnutrido Quissamã adicionada com o pó de folha de mandioca (grupo desnutrido Quissamã + folha de mandioca) e da multimistura (grupo desnutrido Quissamã + multimistura). Para o grupo controle e o grupo Quissamã foram determinados o Coeficiente de Eficácia Protéica e a Razão Protéica Líquida, nos quais o grupo controle mostrou diferenças significativas em relação ao grupo Quissamã que obteve Razão Protéica Líquida e Coeficiente de Eficácia Protéica relativos de $71,54 \%$ e $66,04 \%$, respectivamente. Para os grupos desnutridos foi determinado Coeficiente de Eficácia Proteíca modificado, sendo o grupo desnutrido controle diferente significativamente dos grupo desnutrido Quissamã, grupo desnutrido Quissamã + folha de mandioca e grupo desnutrido Quissamã + multimistura que apresentaram Coeficiente de Eficácia Protéica relativo de $78,10 \%, 75,72 \%$ e $74,67 \%$ respectivamente. Conclui-se que a adição da multimistura
\end{abstract}

\footnotetext{
(1) Departamento de Nutrição e Dietética, Faculdade de Nutrição, Universidade Federal Fluminense. Estrada Caetano Monteiro, 601, Rua 2, Lote 3, Condomínio Ubá VIII, Pendotiba, Niterói, RJ, Brasil. Correspondência para/Correspondence to: G.T.Boaventura. E-mail: gibsontb@gbl.com.br

(2) Nutricionistas, Faculdade de Nutrição, Universidade Federal Fluminense.
} 
ou do pó de folha de mandioca não causou impacto sobre a qualidade da dieta estabelecida em Quissamã, não tendo melhorado sua capacidade de recuperar a desnutrição.

Termos de indexação: multimistura, pó de folha de mandioca, dieta, ratos, qualidade protéica, qualidade dos alimentos.

\begin{abstract}
The following experiment tested the quality of proteins present in the diet of undernourished children in the city of Quissamã, Rio de Janeiro, and then conducted the same tests adding variables: multi-mixture or powder of cassava leaf. The subjects used were 48 Rattus norvergicus, Wistar, males, 24 days old, and weighing $58.95 \mathrm{~g}$. They were fed water and ration ad libitum. In the first phase, called Undernourishment, the animals were divided into three groups: control group, Quissamã group and no proteins group. The control group was fed a ration based on casein and the Quissamã group was fed a ration based on the Quissamã diet. Both of these groups had 8 rats. The no proteins group, with 32 animals, was fed during 10 days a diet with no proteins. In the second phase, called Recovery, which lasted for 18 days, the control group and Quissamã group were fed the same diet. The no proteins group was subdivided into four groups: the undernourished control group, which was fed the same diet as that of the control group; the undernourished Quissamã group, which was fed the same diet as that of the Quissamã group; the undernourished Quissamã group plus powder of cassava leaf; and the undernourished Quissamã group plus multi-mixture. Then, the Protein Efficiency Ratio and the Net Protein Retention were determined for both the control group and the Quissamã group. The results showed significant statiscal differences between these two groups, with the Quissamã Group reaching relative Net Protein Retention and Protein Efficiency Ratio of $71.54 \%$ and 66.04 respectively, in relation to the control Group. The Protein Efficiency Ratio Modified was determined for the undernourished groups. The undernourished control group showed significant statiscal differences in relation to the other groups. In this case, the undernourished Quissamã group, the undernourished Quissamã group plus powder of cassava leaf and the undernourished Quissamã group plus multi-mixture reached Relative Protein Efficiency Ratio Modified of $78.10 \%, 75.72 \%$ and $74.67 \%$ respectively in relation to the undernourished control group. These tests showed that the presence of the multi-mixture or the powder of cassava leaf in the Quissamã diet had no positive effects in the diet quality since there were no signs of improvement of undernourishment in the animals tested.
\end{abstract}

Index terms: multi-mixture, powder of cassava leaf, diet, rats, protein quality, food quality.

\section{INTRODUÇÃO}

O uso das farinhas múltiplas ou multimisturas, mistura de alimentos não convencionais que enriquecem a alimentação habitual em minerais e vitaminas, começou, no Brasil, há alguns anos, na região de Santarém, no Pará. Devido a falta de recursos alimentares, houve procura de alternativas na produção local, que tivessem alto valor nutritivo, embora não fossem tradicionalmente consumidos pela população. Desta maneira, utilizou-se o farelo de arroz e folhas verdes e, pouco a pouco, foram sendo incorporados outros alimentos, como as sementes trituradas e o pó de casca de ovo (Brandão \& Brandão, 1996).

Segundo Beausset (1992), a multimistura começou a ser difundida em todo país com o apoio da Conferência Nacional de Bispos do Brasil (CNBB) e, há alguns anos, vem sendo usada, oficiosamente, em alguns serviços da rede governamental de saúde.

Documentos divulgados pelo Instituto Nacional de Alimentação e Nutrição (Instituto Nacional..., 1995) e pelo Conselho Federal... (1996) demonstraram um posicionamento contrário a utilização da multimistura, devido a escassez de trabalhos científicos que comprovem a utilização desses alimentos.

Torin et al. (1996) destaca a urgência em estabelecer a composição química da multimistura, bem como a realização de estudos bioquímicos e nutricionais acerca dos efeitos resultantes das interações dos seus constituintes. Fárfan (1998) destaca também que qualquer programa de intervenção alimentar deveria considerar os princípios da declaração de Helsinki e as definições técnicas para alimento aceitas pelo Codex Alimentarius.

A Secretaria Municipal de Saúde (SMS) do município de Quissamã, Rio de Janeiro (RJ), preocupada com o problema da desnutrição comprovada em crianças do município e verificando a necessidade de implantação de ações que atendam a esta demanda, vem implementando, no atendimento ambulatorial à pacientes de baixo peso, o uso de uma multimistura (Scudieri et al., 1994).

O trabalho de distribuição e acompanhamento desta mistura aos usuários vem sendo desenvolvido pela equipe multiprofissional da Secretaria Municipal de Saúde, 
atuando nas áreas centrais e distritais deste município, realizando inquéritos recordatórios sobre o consumo alimentar de crianças na faixa etária de zero a 5 anos, participantes do Programa da Multimistura, com o objetivo de traçar um perfil alimentar destas crianças.

Embora a composição da multimistura sofra algumas alterações durante o ano (Câmara \& Madruga, 1996; Chiappini et al., 1996; Sant'ana et al., 1996), em decorrência da safra de hortifrutigranjeiros, tais ingredientes são preparados separadamente seguindo os procedimentos descritos pelo Serviço Nacional de Aprendizagem Rural (Serviço Nacional..., 1994), nas seguintes proporções: $130 \mathrm{~g}$ de farinha de trigo; $130 \mathrm{~g}$ de farelo de trigo; $130 \mathrm{~g}$ de farelo de arroz; $130 \mathrm{~g}$ de fubá; $30 \mathrm{~g}$ de pó de folha de mandioca; 20 g de semente de abóbora triturada; 20 g de semente de girassol triturada, e 10 g de pó da casca de ovo. Esta farinha vem sendo distribuída conforme preconizado por Brandão \& Brandão (1996), totalizando 600 gramas por mês para cada criança, considerando o consumo de 20 gramas por dia.

Dentre os ingredientes que constituem a multimistura, vem chamando atenção o pó de folha de mandioca (Manihot esculenta Crantz) produzido a partir das folhas extraídas de plantações comerciais. Não se deve esquecer que o desperdício das folhas é grande em todas as regiões do Brasil (Fundação Instituto..., 1978) e que são antigos os estudos e recomendações para o aproveitamento da parte aérea da planta da mandioca (hastes, ramos e folhas) na alimentação animal, porém, pouco estudada como alimento humano (Pechnik et al., 1962; Vitti et al., 1971), embora ela já seja usada, em diversos países da África com este propósito (Centro de Raízes..., 1995). Brandão \& Brandão (1996) consideraram a composição química da folha de mandioca e da multimistura bastante favorável para o uso na alimentação humana.

A qualidade nutricional da proteína varia com sua origem. As proteínas de origem vegetal são de baixo valor biológico, principalmente porque são deficientes em alguns aminoácidos essenciais, ou a relação entre eles é desequilibrada. Na luta contra a falta de proteínas, vários autores exaltam a importância do aproveitamento das folhas na alimentação humana, frisando as possibilidades que essa matéria-prima, atualmente pouco utilizada e praticamente desperdiçada, pode oferecer como fonte protéica (Pechnick et al., 1962).

Bicudo et al. (1996) analisaram a recuperação ponderal e o coeficiente de eficácia alimentar em ratos desnutridos quando alimentados com dietas contendo multimistura, fubá, farinha de trigo, farelo de trigo, casca de ovo e folha seca de mandioca. Costa et al. (1996b) avaliaram a influência da multimistura básica no município de Quissamã, RJ, adicionada a uma dieta à base de caseína, através dos métodos de coeficiente de digestibilidade aparente e variação de peso de ratos previamente desnutridos. Nos dois trabalhos os resultados dos grupos adicionados foram inferiores aos dos grupos referência.

Este trabalho avaliou o efeito da adição da multimistura e do pó de folha de mandioca na dieta elaborada com base no perfil alimentar de crianças desnutridas, traçado pela Secretaria Municipal de Saúde do Município de Quissamã, RJ, através de ensaios com animais experimentais.

\section{MATERIAL E MÉTODOS}

\section{Delineamento experimental}

O ensaio biológico foi desenvolvido em duas fases, durante 28 dias, com 48 ratos.

Na primeira fase denominada de Desnutrição, os animais foram distribuídos em Grupo Controle (GC) alimentado com ração à base de caseína, Grupo Quissamã (GQ) alimentado com ração à base da dieta estabelecida em Quissamã, ambos com 8 animais, e Grupo Aprotéico (GA) com 32 animais recebendo uma dieta isenta de proteínas durante 10 dias.

Na segunda fase, denominada de Recuperação, com duração de 18 dias, os GC e GQ permaneceram recebendo a mesma ração. O Grupo Aprotéico foi desmembrado em grupos de 8 animais cada, denominados Grupo Desnutrido Controle (GDC) alimentado com a mesma ração do GC, e mais dois Grupos Desnutridos, recebendo a mesma ração do GDQ, adicionada do pó de folha de mandioca $(G D Q+F M)$ e da multimistura $(G D Q+M M)$. Os animais foram mantidos individualmente em gaiolas de polipropileno, em ambiente com temperatura e iluminação controladas. A água e a ração foram ofertadas ad libitum, sendo o peso registrado semanalmente e o consumo registrado diariamente.

\section{Material}

Foram utilizados Rattus norvergicus, variedade albinus, Rodentia mammalia da raça Wistar, machos, com idade média de 24 dias, oriundos do Laboratório de Nutrição Experimental (LABNE) do Departamento de Nutrição e Dietética da Faculdade de Nutrição da Universidade Federal Fluminense.

\section{Dietas e rações}

A dieta estabelecida em Quissamã foi elaborada com base no inquérito recordatório (Tabela 1), realizado 
pela equipe de profissionais da Secretaria Municipal de Saúde da Prefeitura de Quissamã, RJ, com os pais das crianças inscritas e participantes do projeto Perfil Alimentar das Crianças do Programa da Multimistura. Os inquéritos recolhidos foram analisados pelo software Sistema de Apoio a Decisão, versão 2.5, da Escola Paulista de Medicina, SP. Esta dieta serviu de base para o preparo da ração Quissamã utilizada no ensaio.

As amostras dos ingredientes que constituem a multimistura foram coletadas junto à Secretaria Municipal de Saúde da Prefeitura de Quissamã.

Foram utilizadas, no ensaio biológico, ração Controle à base de caseína e a ração Quissamã, adicionada

Tabela 1. Lista de alimentos utilizada para o preparo da dieta estabelecida em Quissamã, RJ.

\begin{tabular}{lc}
\hline Alimentos & Quantidade (g) \\
\hline Abóbora cozida & 2,1 \\
Açúcar refinado & 23,5 \\
Arroz branco cozido & 94,3 \\
Banana & 53,9 \\
Batata cozida com sal & 36,4 \\
Café solúvel & 70,0 \\
Carne moída & 16,4 \\
Cenoura cozida & 6,2 \\
Couve cozida & 7,6 \\
Feijão cozido & 96,4 \\
Frango cozido & 26,8 \\
Laranja & 19,2 \\
Leite tipo C & 306,8 \\
Maçã com casca & 23,1 \\
Macarrão cozido & 12,6 \\
Mandioca doce & 49,6 \\
Mamão papaia & 29,4 \\
Nescau & 9,3 \\
Óleo de soja & 0,7 \\
Ovo cozido & 21,4 \\
Pão francês & 37,0 \\
\hline Total & 942,7 \\
\hline Fonte: Scudieri & \\
\hline & \\
\hline
\end{tabular}

Fonte: Scudieri (1994). ou não do pó de folha de mandioca e da multimistura. Estas foram preparadas no LABNE com $10 \%$ de proteína, adicionadas das misturas de minerais e vitaminas segundo as normas do Committee on Laboratory... (1979), modificadas segundo as recomendações da American Institute of Nutrition-93 (Reeves et al.,1993), sendo as misturas de minerais e vitaminas preparadas segundo a Association of Official Analytical Chemists (Association..., 1975).

A ração Quissamã, adicionada ou não da multimistura e do pó de folha de mandioca, foi preparada de acordo com a composição centesimal (Tabela 2). Estas rações foram confeccionadas, pesando os ingredientes em balança digital, Toledo ${ }^{\circledR}$ Com precisão de $0,1 \mathrm{~g}$, homogeneizando-os em batedeira industrial, Hobart ${ }^{\circledR}$, com água fervente. A massa obtida foi "peletizada", seca em estufa sob ventilação forçada de ar, à temperatura de $60^{\circ} \mathrm{C}$, por aproximadamente 24 horas e após identificação, armazenada sob refrigeração até o seu uso (Tabela 3 ).

\section{Métodos de análise}

$\mathrm{Na}$ dieta estabelecida em Quissamã, na multimistura, no pó de folha de mandioca e na caseína foram determinados os teores de umidade, cinzas, proteínas e lipídios pelos métodos preconizados pela Association of Official Analytical Chemists (Association..., 1984) e a quantidade de carboidrato foi estabelecida pela fração não protéica.

A ração Quissamã foi avaliada biologicamente através do Net Protein Retention (NPR) e do Protein Efficiency Ratio (PER), segundo De Angelis (1995).

O NPR também conhecido como Razão Protéica Líquida (RPL) é um método que consiste em medir as variações de peso corporal, porém é considerado o peso que o animal teria perdido se não tivesse ingerido a proteína, ou seja, calcula-se a eficiência da proteína em "manter" e "aumentar" o peso corporal. O tempo de experimentação sugerido é de 10 dias. O PER também conhecido como Coeficiente de Eficácia Protéica (CEP) baseia-se na variação de peso corporal. Assumindo que ocorre variação do total de proteína corporal motivada por diferenças da qualidade protéica da dieta, é comum medir-se a variação do peso corporal como um reflexo global da

Tabela 2. Composição centesimal da dieta estabelecida em Quissamã, da multimistura e da farinha de folha de mandioca utilizados no município de Quissamã, RJ.

\begin{tabular}{|c|c|c|c|c|}
\hline Análise & Dieta estabelecida em Quissamã & Multimistura & Farinha de mandioca & Caseína \\
\hline Umidade & 4,63 & 6,50 & 4,91 & 4,99 \\
\hline Cinzas & 3,72 & 7,43 & 6,86 & 0,99 \\
\hline Proteínas & 21,85 & 15,15 & 31,52 & 94,10 \\
\hline Extrato etéreo & 8,15 & 7,06 & 6,22 & - \\
\hline Fração não protéica & 61,64 & 63,86 & 50,49 & - \\
\hline
\end{tabular}


Tabela 3. Composição das rações utilizadas para o ensaio.

\begin{tabular}{|c|c|c|c|c|c|}
\hline Alimentos Rações* & Controle & Quissamã & Quissamã + MM & Quissamã + FM & Aprotéica \\
\hline Caseína ${ }^{1}$ & 847,86 & - & - & - & - \\
\hline Dieta estabelecida em Quissamã ${ }^{2}$ & - & 3599,18 & 1258,56 & 1316,16 & - \\
\hline Folha de mandioca ${ }^{3}$ & - & - & - & 2,88 & - \\
\hline Multimistura $^{3}$ & - & - & 60,48 & - & - \\
\hline Óleo ${ }^{4}$ & 550,20 & 235,80 & 86,40 & 86,40 & 96,00 \\
\hline Mistura de minerais ${ }^{5}$ & 275,10 & 275,10 & 100,80 & 100,80 & 112,00 \\
\hline Mistura de vitaminas ${ }^{5}$ & 78,60 & 78,85 & 28,89 & 28,89 & 32,00 \\
\hline Fibra $^{6}$ & 393,00 & 393,00 & 144,00 & 144,00 & 160,00 \\
\hline Amido de milho ${ }^{7}$ & 4929,24 & 3278,82 & 1200,96 & 1200,96 & 1334,40 \\
\hline Açúcar ${ }^{8}$ & 786,00 & - & - & - & - \\
\hline Colina & 0,20 & 0,20 & 0,07 & 0,07 & 0,08 \\
\hline Total & 7860,20 & 7860,95 & 2880,16 & 2880,16 & 3 200,08 \\
\hline
\end{tabular}

(1) Comercial da Herzog; ${ }^{(2)}$ Elaborada segundo o inquérito da Secretaria Municipal de Saúde do Município de Quissamã, RJ; ${ }^{(3)}$ Alimentos alternativos preparados e consumidos no município de Quissamã, RJ; ${ }^{(4)}$ Liza ${ }^{\circledR}$, Cargill Agrícola Ltda; ${ }^{(5)}$ Preparadas segundo a Association ... (1975) (elaborada no LABNE/UFF); ${ }^{(6)}$ Microcel ${ }^{\circledR}$, Blanver Ltda; ${ }^{(7)}$ Maizena ${ }^{\circledR}$, Refinações de Milho, Brasil Ltda; ${ }^{(8)}$ Fabricante União

(*) Preparada de acordo com as normas do Committee... (1979), modificadas segundo as recomendações da AIN-93 (Reeves et al., 1993 ).

atuação da proteína ingerida. O tempo de experimentação sugerido para o PER é de 28 dias. A ração Quissamã adicionada ou não do pó de folha de mandioca, ou da multimistura foi avaliada através de uma modificação do método do PER, com a redução do seu tempo para 18 dias do ensaio, sendo denominado de Protein Efficiency Ratio modificado (PERm). Para tal, coletou-se o peso do animal, no $10^{\circ} \stackrel{\circ}{1} 4^{\circ} \stackrel{\circ}{ }, 21^{\circ}$ e $28^{\circ}$ dias e a ração consumida diariamente.

Este método foi estipulado para avaliar a capacidade de recuperação do crescimento dos animais, cuja desnutrição foi induzida pelo consumo de ração aprotéica por 10 dias, aplicando-se a mesma fórmula do PER.

Os dados foram apresentados na forma de média (X) e desvio-padrão (DP) acompanhados do coeficiente de variação $(\mathrm{CV})$. Nos resultados relativos às avaliações biológicas, NPR e PER, foram aplicados o teste estatístico de Friedman. Os resultados relativos ao PERm foram avaliados estatisticamente através de análise de variância (ANOVA) (Rodrigues, 1986). Para ambos os testes foram considerados $p \leq 0,05$, como nível de significância. As análises estatísticas foram feitas utilizando-se o pacote estatístico de software STATGRAPHICS Plus, versão 6.0.

\section{RESULTADOS E DISCUSSÃO}

Observando-se as médias referentes ao consumo de ração e proteínas no $10^{\circ}, 18^{\circ}$ e $28^{\circ}$ dias, apresentadas na Tabela 4, não foi encontrada diferença significativa entre os grupos.

O peso médio dos GC e GQ, no 10o dia, foi significativamente diferente ao nível de $p \leq 0,00006$; podendo-se observar para o GC ganho médio de peso de
38,0 g e 20,0 g para o GQ, enquanto no GA, foi observado perda média de $10,0 \mathrm{~g}$. No $14^{\circ}, 21^{\circ}$ e $28^{\circ}$ dias, diferenças significativas ao nível de $\mathrm{p} \leq 0,004$ para os GC e GQ, com variação de peso no $2^{\circ}$ o dia de 108,69 g e 61,93 g, respectivamente (Tabela 5 ).

Na segunda fase do ensaio, foi observado que nos $14^{\circ}, 21^{\circ}$ e $28^{\circ}$ dias não houve diferença estatística de peso entre os grupos desnutridos.

Os resultados de NPR e de PER mostram diferenças significativas ao nível de $p \leq 0,00006$ e de $p \leq 0,004$ entre o GC e o GQ, respectivamente (Tabela 6). Nos dados do PERm (Tabela 7) foram observadas diferenças entre o GDC e os demais grupos desnutridos ao nível de $p \leq 0,03$.

Analisando o consumo médio de proteínas na primeira fase foi observado que o GC ingeriu 10,18 \pm 0,73 g e o GQ 10,63 $\pm 1,75$ g. Na variação de peso, verificou-se ganho de $38,47 \pm 5,54 \mathrm{~g}$ para o GC e 20,50 \pm 4,69 g para o GQ. Conseqüentemente, o NPR destes dois grupos foi 4,78 \pm 0,57 para o GC e 3,42 \pm 0,50 para o GQ. Tentando estabelecer um critério de comparação entre os dois grupos, deduziu-se que para cada grama de proteína ingerida, o GC obteve ganho médio de peso de 3,77 g enquanto o GQ conseguiu 1,92 g.

Quando o índice de crescimento do GQ foi relacionado ao consumo de proteína do GC, verificou-se que o GQ apresentaria apenas um ganho médio de peso de 19,54 g, que seria ainda, inferior ao obtido pelo GC. Partindo do pressuposto que o NPR do GC $(4,78)$ representa $100,00 \%$, verificou-se que o NPR do GQ $(3,42)$, correspondeu apenas a 71,54 \% do NPR do GC. Esses dados sugerem que a qualidade biológica da proteína da ração do GC foi superior a da ração do GQ.

Os percentuais de coeficiente de variação do consumo de ração e de proteína (Tabela 4) e do NPR 
(Tabela 6) durante os 10 dias de ensaio mostraram que os valores do GC foram inferiores ao do GQ, revelando uma homogeneidade maior entre os animais do GC. Em um ensaio biológico realizado por Costa et al. (1996a) foi verificado que o valor de NPR encontrado para o GC $(2,73 \pm 0,69)$ foi bastante inferior ao relatado neste trabalho $(4,79 \pm 0,57)$.

Os dados de consumo médio de proteínas, durante os 28 dias de ensaio, evidenciam que o GC ingeriu 33,96 $\pm 1,38 \mathrm{~g}$, ingestão igual a do GQ que consumiu $33,20 \pm 4,05 \mathrm{~g}$. A variação média de peso do GC foi de 109,75 \pm 7,81 g, contra 63,69 \pm 9,58 g do GQ. No cálculo do PER foi encontrado 3,24 $\pm 0,15$ para o GC e 2,14 $\pm 0,22$ para o GQ. Relacionando este índice de crescimento do GQ com o consumo de proteína do GC, verificou-se que o GQ apresentou apenas um ganho médio de peso de $64,86 \mathrm{~g}$, o qual seria ainda, inferior ao obtido pelo GC. Partindo do pressuposto que o PER do GC $(3,24)$ representa 100,00\%, verificou-se que o PER do GQ $(2,14)$, correspondeu apenas a $66,04 \%$ do PER do GC. Este fato revela que a qualidade protéica da ração que utiliza a dieta estabelecida em Quissamã é inferior a do Grupo Controle. Analisando os resultados do coeficiente de variação de consumo de ração, de proteína e de PER, durante os 28 dias de ensaio, verificou-se que os valores do GC se mostraram mais homogêneos do que os do GQ.

Resultados semelhantes foram encontrados por Di Pietro et al. (1996), que utilizando os métodos de
Curva de Peso, de Coeficiente de Eficácia Alimentar e de Coeficiente de Eficácia Protéica para avaliar a ração típica da creche adicionada de farelo de trigo e de farelo de arroz, obtiveram um Coeficiente de Eficácia Protéica, menor do que a ração do Grupo Controle.

Para análise dos dados de PERm foram utilizados apenas os grupos da segunda fase que sofreram o processo de desnutrição, o GDQ+FM apresentou maior consumo protéico $(21,95 \pm 2,53$ g) que o $\operatorname{GDC}(19,25 \pm 3,22$ g). Esta diferença não foi significativa. Embora, tenha sido o grupo que alcançou o maior PERm, $(3,79 \pm 0,50)$. Por sua vez o GDQ e o GDQ+MM, apresentaram basicamente o mesmo consumo de proteína $(20,31 \mathrm{~g})$ e valores para PERm semelhantes, sugerindo que o crescimento dos ratos foi proporcional ao consumo de proteína. Com base no Coeficiente de Variação de consumo de ração e proteína dos grupos, foi observado que o GDQ+MM obteve o maior valor, sendo então o menos homogêneo, enquanto o GDQ +FM foi, neste caso, o mais homogêneo. O GDC e o GDQ obtiveram percentuais bem semelhantes para o consumo protéico, porém maiores do que o GDQ+FM e menores do que o GDQ+MM.

Silva et al. (1996) avaliando a qualidade protéica de uma dieta consumida no Instituto Nacional de Pesquisas da Amazônia (INPA), utilizaram como parâmetro de avaliação biológica o Índice de Crescimento, o Coeficiente de Eficácia Alimentar, o Coeficiente de Eficácia Protéica, a Razão Protéica

Tabela 4. Consumo de ração (g) e de proteína (g) dos Grupos Controle (CG), Quissamã (GQ), Desnutrido Controle (GDC), Desnutrido Quissamã (GDQ), Desnutrido Quissamã adicionado de Folha de Mandioca (GDQ+FM) e Desnutrido Quissamã adicionado da Multimistura $(\mathrm{GDQ}+\mathrm{MM})$ nos diferentes ensaios realizados durante 28 dias.

\begin{tabular}{|c|c|c|c|c|c|c|}
\hline \multirow[t]{2}{*}{ Consumo } & \multicolumn{2}{|c|}{10 dias } & \multicolumn{2}{|c|}{18 dias } & \multicolumn{2}{|c|}{28 dias } \\
\hline & Ração & Proteína & Ração & Proteína & Ração & Proteína \\
\hline $\mathrm{GC}(\mathrm{n}=8) \overline{\mathrm{X}} \pm \mathrm{DP}$ & $101,88 \pm 7,37^{\mathrm{a}}$ & $10,18 \pm 0,73^{a}$ & $238,63 \pm 12,43^{a}$ & $23,86 \pm 1,24^{\mathrm{a}}$ & $339,63 \pm 13,81^{\mathrm{a}}$ & $33,96 \pm 1,38^{a}$ \\
\hline CV (\%) & 7,24 & 7,24 & 5,51 & 5,21 & 4,06 & 4,06 \\
\hline GQ $(n=8) \bar{X} \pm D P$ & $106,34 \pm 17,59^{\mathrm{a}}$ & $10,63 \pm 1,75^{\mathrm{a}}$ & $231,38 \pm 32,18^{a}$ & $23,13 \pm 3,21^{\mathrm{a}}$ & $332,00 \pm 40,58^{a}$ & $33,2 \pm 4,05^{a}$ \\
\hline CV (\%) & 16,54 & 16,54 & 13,91 & 13,91 & 12,22 & 12,22 \\
\hline $\mathrm{GA}(\mathrm{n}=32) \bar{X} \pm \mathrm{DP}$ & $44,63 \pm 7,34^{*}$ & & & & & \\
\hline CV (\%) & 16,43 & & & & & \\
\hline $\mathrm{GDC}(\mathrm{n}=8) \overline{\mathrm{X}} \pm \mathrm{DP}$ & & & $192,56 \pm 32,29^{a}$ & $19,25 \pm 3,22^{a}$ & & \\
\hline CV (\%) & & & 16,77 & 16,77 & & \\
\hline GDQ $(n=8) \bar{X} \pm$ DP & & & $200,75 \pm 33,92^{a}$ & $20,07 \pm 3,39^{a}$ & & \\
\hline CV (\%) & & & 16,89 & 16,89 & & \\
\hline $\mathrm{GDQ}+\mathrm{FM}(\mathrm{n}=8) \overline{\mathrm{X}} \pm \mathrm{DP}$ & & & $219,56 \pm 25,39^{a}$ & $21,95 \pm 2,53^{\mathrm{a}}$ & & \\
\hline CV (\%) & & & 11,56 & 11,56 & & \\
\hline $\mathrm{GDQ}+\mathrm{MM}(\mathrm{n}=8) \bar{X} \pm \mathrm{DP}$ & & & $205,69 \pm 39,67$ & $20,56 \pm 3,96$ & & \\
\hline CV $(\%)$ & & & 19,28 & 19,28 & & \\
\hline
\end{tabular}

(a;b) Letras diferentes demonstram que o teste de Friedman, duas amostras, é estatisticamente significante ao nível de $\mathrm{p} \leq 0,05$

* O consumo do GA não foi considerado para análise estatística 
Tabela 5. Peso médio (g) inicial, semanal e final dos Grupos Controle (CG), Quissamã (GQ), Desnutrido Controle (GDC), Desnutrido Quissamã (GDQ), Desnutrido Quissamã adicionado de Folha de Mandioca (GDQ =FM) e Desnutrido Quissamã adicionado da Multimistura $(\mathrm{GDQ}+\mathrm{MM})$ nos diferentes ensaios realizados durante 28 dias.

\begin{tabular}{|c|c|c|c|c|c|c|}
\hline $\begin{array}{ll}\text { Grupos } & \text { Peso } \\
\end{array}$ & $\mathrm{PO}$ & P7* & $\mathrm{P} 10^{* * *}$ & $\mathrm{P} 14^{* *}$ & $\mathrm{P} 21^{* *}$ & $\mathrm{P} 28^{* *}$ \\
\hline$G C(n=8) \bar{X} \pm D P$ & $59,50 \pm 7,38$ & $86,66 \pm 7,49^{a}$ & $97,97 \pm 7,40^{\mathrm{a}}$ & $112,25 \pm 7,8^{\mathrm{a}}$ & $151,69 \pm 7,24^{\mathrm{a}}$ & $168,19 \pm 7,30^{\mathrm{a}}$ \\
\hline CV $(\%)$ & 12,40 & 8,64 & 7,55 & 6,95 & 4,77 & 4,34 \\
\hline $\mathrm{GQ}(\mathrm{n}=8) \bar{X} \pm \mathrm{DP}$ & $59,63 \pm 7,70$ & $73,59 \pm 8,75^{\mathrm{b}}$ & $80,13 \pm 8,53^{\mathrm{b}}$ & $88,94 \pm 6,22^{b}$ & $111,31 \pm 7,04^{\mathrm{b}}$ & $121,56 \pm 8,54^{\mathrm{b}}$ \\
\hline CV $(\%)$ & 12,91 & 11,88 & 10,64 & 7,00 & 6,32 & 7,03 \\
\hline$G A(n=32) X \pm D P$ & $57,74 \pm 9,45$ & & $47,88 \pm 7,45^{c}$ & & & \\
\hline CV (\%) & 16,36 & & 15,56 & & & \\
\hline $\operatorname{GDC}(n=8) \bar{x} \pm D P$ & & & $48,56 \pm 6,14^{c}$ & $65,31 \pm 12,73^{\mathrm{c}}$ & $101,13 \pm 19,04$ & $120,9418,12^{b}$ \\
\hline CV $(\%)$ & & & 12,65 & 12,50 & 18,82 & 14,99 \\
\hline GDQ $(n=8) \bar{X} \pm D P$ & & & $47,19 \pm 8,77^{\mathrm{c}}$ & $63,69 \pm 9,73^{c}$ & $90,19 \pm 16,63$ & $105,44 \pm 17,30^{\mathrm{b}}$ \\
\hline CV $(\%)$ & & & 18,59 & 15,28 & 18,44 & 16,41 \\
\hline $\mathrm{GDQ}+\mathrm{FM}(\mathrm{n}=8) \bar{X} \pm \mathrm{DP}$ & & & $51,50 \pm 8,19^{c}$ & $69,50 \pm 8,59^{c}$ & $98,13 \pm 11,59$ & $113,81 \pm 12,58^{b}$ \\
\hline CV $(\%)$ & & & 15,89 & 12,35 & 11,81 & 11,05 \\
\hline $\mathrm{GDQ}+\mathrm{MM}(\mathrm{n}=8) \overline{\mathrm{X}} \pm \mathrm{DP}$ & & & $47,88 \pm 9,73^{c}$ & $63,63 \pm 11,49^{\mathrm{c}}$ & $90,81 \pm 17,39$ & $106,13 \pm 20,37^{b}$ \\
\hline CV $(\%)$ & & & 20,33 & 18,05 & 19,15 & 19,20 \\
\hline
\end{tabular}

${ }^{(a ; b)}$ Letras sobrescritas diferentes demonstram que o teste de Friedman, duas amostras, é estatisticamente significante ao nível de ${ }^{*} \mathrm{p} \leq 0,03 ;{ }^{* *} \mathrm{p} \leq 0,00 ;{ }^{* * *} \mathrm{p} \leq 0,00006$

Tabela 6. Dados de NPR, PER e resultados relativos dos Grupos Controle (CG) e Quissamã (GQ) nos ensaios de 10 e 28 dias.

\begin{tabular}{lcc}
\hline Grupos & Métodos biológicos & PER $^{* *}$ \\
\hline GC $(\mathrm{n}=8) \bar{X} \pm$ DP & $4,78 \pm 0,57^{\mathrm{a}}$ & $3,24 \pm 0,15^{\mathrm{a}}$ \\
$\mathrm{CV}(\%)$ & 11,98 & 5,21 \\
Relativo (\%) & 100 & 100 \\
GQ $(\mathrm{n}=8) \overline{\mathrm{X}} \pm \mathrm{DP}$ & $3,42 \pm 0,50^{\mathrm{b}}$ & $2,14 \pm 0,22^{\mathrm{b}}$ \\
CV $(\%)$ & 15,92 & 8,52 \\
Relativo (\%) & 71,54 & 66,04
\end{tabular}

${ }^{(a ; b)}$ Letras diferentes demonstram que o teste de Friedman, duas amostras, é estatisticamente significante ao nível de ${ }^{*} \mathrm{p} \leq 0,00006 ;{ }^{* *} \mathrm{p} \leq 0,004$

Líquida, o Coeficiente de Digestibilidade e o Valor Biológico, e verificaram que os valores do Coeficiente de Digestibilidade apresentaram-se significativamente inferiores $(85,10 \% \pm 1,30)$ ao GC $(95,235 \% \pm 0,9157)$ embora não tenham apresentado diferenças estatísticas nos demais parâmetros. Relataram, ainda, que a fonte protéica da dieta consumida no INPA apresentou Valor Biológico equivalente ao da dieta Controle. Sendo assim, estes autores apresentaram resultados contrários em relação aos dados do PER deste trabalho.

Costa et al. (1996b), realizando um trabalho semelhante, encontraram, na primeira fase do experimento, valores iguais $(64,0 \%)$ para os grupos alimentados à base de caseína. Na segunda fase, encontraram valores de 45,38 \% na variação de peso no Grupo Basal (GB), 87,17\%
Tabela 7. Dados de PERm e resultados relativos dos Grupos Desnutridos Controle (GDC) e Desnutrido Quissamã (GDQ), Desnutridos Quissamã adicionadas da multimistura $(\mathrm{GDQ}+\mathrm{MM})$ e do pó de folha de mandioca $(\mathrm{GDQ}+\mathrm{FM})$.

\begin{tabular}{|c|c|}
\hline Grupos & PERm \\
\hline $\operatorname{GDC}(n=8) \bar{X} \pm D P$ & $3,79 \pm 0,50^{\mathrm{a}}$ \\
\hline CV $(\%)$ & 9,45 \\
\hline Relativo (\%) & 100 \\
\hline GDQ $(n=8) \bar{X} \pm D P$ & $2,96 \pm 0,21^{b}$ \\
\hline CV $(\%)$ & 6,97 \\
\hline Relativo (\%) & 78,10 \\
\hline $\mathrm{GDQ}+\mathrm{FM}(\mathrm{n}=8) \overline{\mathrm{X}} \pm \mathrm{DP}$ & $2,87 \pm 0,19^{b}$ \\
\hline CV $(\%)$ & 7,22 \\
\hline Relativo (\%) & 75,72 \\
\hline $\mathrm{GDQ}+\mathrm{MM}(\mathrm{n}=8) \overline{\mathrm{X}} \pm \mathrm{DP}$ & $2,83 \pm 0,23^{b}$ \\
\hline CV $(\%)$ & 8,13 \\
\hline Relativo (\%) & 74,67 \\
\hline
\end{tabular}

(a;b) Letras diferentes demonstram que a análise de variância das amostras são estatisticamente significantes ao nível de $p \leq 0,03$

no Grupo Desnutrido Basal (GDB) e 80,41\% no Grupo Desnutrido Multimistura (GDM), sendo que a recuperação dos animais deste grupo não dependeu da adição da multimistura. Neste trabalho foi encontrada uma variação de peso de $71,00 \%$ para o GC, um valor superior ao citado por Costa et al. (1996a), mesmo tendo sido utilizado o mesmo percentual de caseína, e 72,00\% para o GDC, 
inferior ao GDB. Para o GQ foi observado um ganho ponderal de $121,00 \%$ e para o GDQ e o GDQ + MM, $123,00 \%$ e $122,00 \%$, respectivamente. Esses valores mostraram que a recuperação destes animais também não dependeram da adição da multimistura. Bion et al. (1997), analisando uma dieta constituída de feijão e arroz, suplementada com uma multimistura semelhante a utilizada neste trabalho, avaliou indicadores biológicos como NPR e PER, tendo encontrado valores inferiores, possivelmente em função da qualidade de alimentos que compunham as rações utilizadas e do tempo maior de experimentação utilizado.

Os alimentos que fizeram parte da dieta estabelecida em Quissamã estão descritos na Tabela 1, onde de acordo com a distribuição dos macronutrientes foi obtido 43,00 g de proteínas, sendo $24,60 \mathrm{~g}$ de Alto Valor Biológico (10,22 g de leite, 2,60 g de ovo, 5,03 g de carne bovina, 6,78 g de aves); 17,00 g de lipídios e 176,00 g de carboidratos, perfazendo um total de $1005 \mathrm{kcal}$. Esses valores demonstram que a qualidade da dieta consumida pelas crianças não deve ser considerada como um indicador da desnutrição, visto que apresenta $16,70 \%$ de proteína. Foi observado, também, que o total de calorias atende apenas as necessidades energéticas das crianças estudadas na faixa de zero a 12 meses, onde os meninos necessitam de 470 - $1050 \mathrm{kcal} / \mathrm{dia}$ e as meninas 445 - $975 \mathrm{Kcal} / \mathrm{dia}$. As necessidades para crianças maiores são diferentes, de 1 a 2 anos os meninos necessitam de $1200 \mathrm{kcal} / \mathrm{dia}$ e as meninas de $1140 \mathrm{kcal} / \mathrm{dia}$; de 2 a 3 anos os meninos necessitam de $1410 \mathrm{kcal} / \mathrm{dia}$ e as meninas $1310 \mathrm{kcal} / \mathrm{dia}$; de 3 a 4 anos, $1560 \mathrm{kcal} /$ dia para os meninos e $1440 \mathrm{kcal} / \mathrm{dia}$ para as meninas e de 4 a 5 anos $1690 \mathrm{kcal} / \mathrm{dia}$ para os meninos e $1670 \mathrm{kcal} / \mathrm{dia}$ para as meninas. Visto que a qualidade protéica da dieta consumida atende, de forma satisfatória, os princípios nutritivos e, como pode ser notado, as calorias da dieta estão abaixo do recomendado pela Organización Mundial de la Salud (Organización..., 1985), pode-se sugerir que, mesmo sem a adição da multimistura ou do pó de folha de mandioca, o organismo destas crianças passou a desviar grande parte das proteínas da sua função principal, para utilizá-la como fonte de energia.

Quando esta dieta foi transformada em rações para serem utilizadas durante os ensaios, o GQ e o GDQ que receberam a ração Quissamã equilibrada nos princípios nutritivos para atender o animal, foram capazes de promover o crescimento e a recuperação dos animais, respectivamente.

Em relação à adição da multimistura e do pó de folha de mandioca na ração foi observado que a adição da multimistura não influenciou na recuperação do peso corporal nem na promoção de crescimento, quando comparada com a ração Quissamã sem adição. A adição do pó de folha de mandioca, por sua vez, promoveu uma melhora no crescimento dos animais, contudo ela pode ser considerada sem significância.

\section{CONCLUSÃO}

Baseado nos resultados dos indicadores biológicos NPR e PER utilizados neste experimento, foi concluído que, a ração consumida foi suficiente para promover o crescimento e a sua manutenção de forma satisfatória, sendo capaz de permitir a recuperação dos animais.

Entretanto, a adição da multimistura e do pó de folha de mandioca, com base no indicador biológico PERm, não causou impacto sobre a qualidade da ração Quissamã não tendo melhorado sua capacidade de recuperar a desnutrição. Ressalta-se a importância da realização de mais estudos para justificar o uso na alimentação humana destes alimentos não convencionais.

\section{REFERÊNCIAS BIBLIOGRÁFICAS}

ASSOCIATION OF OFFICIAL ANALYTICAL CHEMISTS. Official methods of analysis. 12.ed. Washington DC, 1975. p.857.

ASSOCIATION OF OFFICIAL ANALYTICAL CHEMISTS. Official methods of analysis. 14.ed. Washington DC, 1984. p.409-757.

BEAUSSET, I. Estudio de las bases cientificas para el uso de alimentos alternativos en la nutrición humana. Brasília : INAN, 1992. 36p.

BICUDO, M.H., MAFFEI, H.V.L., CASSETARI, M.L. Ganho ponderal de ratos desnutridos recebendo "Multi-Mistura", com diferentes proporções de farelos de cereais. In: CONGRESSO NACIONAL DA SOCIEDADE BRASILEIRA DE ALIMENTAÇÃO E NUTRIÇÃO, 4., 1996, São Paulo. Resumos..., São Paulo : SBAN, 1996. Seção NE20.

BION, F.M., PESSOA, D.C.N.P., LAPA, M.A.G., CAMPOS, F.A,C.S., ANTUNES, N.L.M., LOPES, S.M.L. Uso de uma multimistura como suplemento alimentar: estudo em ratos. Archivos Latinoamericanos de Nutrición, Guatemala, v.47, n.3, p.242-247, 1997.

BRANDÃO, C.T., BRANDÃO, R.F. Alimentação alternativa. Brasília : Centro de Pastoral Popular, 1996. 68p.

CÂMARA, F.S., MADRUGA, M.S. Avaliação química e nutricional de uma multimistura utilizada com suplemento alimentar na alimentação humana. In: CONGRESSO BRASILEIRO DE CIÊNCIA E TECNOLOGIA DE ALIMENTOS, 5.,1996, Poços de Caldas. Anais..., Poços de Caldas : SBCTA, 1996. Seção 6. p.91.

CENTRO DE RAÍZES TROPICAIS. Revisão bibliográfica selecionada: folhas de mandioca. São Paulo: Universidade Estadual Paulista, 1995. 14p.

CHIAPPINI, C.C.J., MARTINS, A.S.A., ABREU, A.V.D. Composição química de multimistura e de seus ingredientes. I. Composição centesimal. Resultados Parciais. In: CONGRESSO BRASILEIRO DE CIÊNCIA E TECNOLOGIA DE ALIMENTOS, 15., 1996, Poços de Caldas. Anais... Poços de Caldas : SBCTA, 1996. Seção 6. p.80.

COMMITTEE ON LABORATORY ANIMAL DIETS. Assembly of Life Sciences National Research Council. Nutritions Abstracts and Reviews, Serie B, Aberdeen GB, v.40, p.413-419, 1979. 
CONSELHO FEDERAL DE NUTRICIONISTAS. Posicionamento do Conselho Federal de Nutricionistas quanto à multimistura. Brasília, fevereiro 1996. $5 \mathrm{p}$.

COSTA,P.V., CHIAPPINI, C.C.J., BOAVENTURA, G.T. Avaliação da multimistura básica de Quissamã, RJ, como suplemento alimentar. In: CONGRESSO BRASILEIRO DE NUTRIÇÃO, 14., 1996, Belo Horizonte. Anais.... Belo Horizonte : CONBRAN, 1996a. p.89.

COSTA, P.V., CHIAPPINI, C.C.J., BOAVENTURA, G.T. Variação de peso em ratos e digestibilidade da multimistura básica utilizada no município de Quissamã, RJ. In: CONGRESSO NACIONAL DA SOCIEDADE BRASILEIRA DE NUTRIÇÃO, 14., 1996. São Paulo. Anais... São Paulo : SBAN, 1996b. NE-35.

DE ANGELIS, R.C. Valor nutricional das proteínas: métodos de avaliação. Cadernos de Nutrição, São Paulo, v.10, p.8-29, 1995.

DI PIETRO, P.F., AVANCINI, S.R.P., KAZAPI, I.M., TRAMONTE, V.L.C.G., FACCIN, G.L. Estudo experimental em ratos da qualidade protéica de um dia alimentar de crianças préescolares com ou sem suplementação de farelo de trigo e arroz. In: CONGRESSO NACIONAL DA SOCIEDADE BRASILEIRA DE ALIMENTAÇÃO E NUTRIÇÃO, 4., 1996, São Paulo. Anais.... São Paulo : SBAN, 1996. NE19.

FÁRFAN, J.A. Alimentação alternativa: análise crítica de uma proposta de intervenção nutricional. Cadernos de Saúde Pública, Rio de Janeiro, v.14, n.1, p.205-212, 1998.

FUNDAÇÃO INSTITUTO DE DESENVOLVIMENTO ECONÔMICO E SOCIAL DO RIO DE JANEIRO. Produtos selecionados: mandioca, milho e tomate. Oportunidades agroindustriais - Localização e identificação. Rio de Janeiro, 1978. p.30-94.

INSTITUTO NACIONAL DE ALIMENTAÇÃO E NUTRIÇÃO. Carta Circular n.04/95-P/INAN-BSB, Brasília, novembro 1995. 4p.

ORGANIZACIÓN MUNDIAL DE LA SALUD. Necesidades de energia y de proteínas. Ginebra, 1985. 220p. (Serie de Informes Técnicos, 724).

PECHNIK, E., GUIMARÃES, L.R., PANEK, A. Sobre o aproveitamento da folha de mandioca (Manihot $\mathrm{sp}$ ) na alimentação humana. II. Valor Nutritivo. Arquivos Brasileiros de Nutrição, Rio de Janeiro, v.18, n.1-2, p.11-23, 1962.

REEVES, P.G., NIELSEN, F.H., FAHEY Jr., G.C.F. AIN-93 purified diet of laboratory Rodents: final report of the American Institute of Nutrition ad hoc writing Committee on the Reformulation of the AIN-76A Rodents Diet. Journal of Nutrition, Bethesda, v.123, n.6, p.1939-1951, 1993.

RODRIGUES, P.C. Bioestatística. Niterói : EDUFF, 1986. 74p.

SANT'ANA, L.F.R., COSTA, N.M.B., FERREIRA, G., OLIVEIRA, M.G.A, MONTEIRO, J.B.R. Valor Nutritivo de "multimisturas" utilizadas como alternativa alimentar. In: CONGRESSO NACIONAL DA SOCIEDADE BRASILEIRA DE ALIMENTAÇÃO E NUTRIÇÃO, 4., 1996, São Paulo. Anais... São Paulo : SBAN, 1996. p.BA 9.

SCUDIERI, A.P.B., SOUZA, E.D.M., RODRIGUES, J.A.O., SILVEIRA, L.C., BATISTA, S.M.S. Sub-programa da multimistura. Quissamã : Prefeitura Municipal de Quissamã/Secretaria Municipal de Saúde, 1994. 19p.

SERVIÇO NACIONAL DE APRENDIZAGEM RURAL. Alimentação alternativa. Salvador, 1994. 56p.

SILVA, C.T.C., PICANÇO, N.S., MOREIRA-JUNIOR, F.S., YUYAMA, L.K.O., AGUIAR, J.P.L. Avaliação da qualidade protéica de uma dieta consumida no Instituto Nacional de Pesquisas da Amazônia. In: CONGRESSO NACIONAL DA SOCIEDADE BRASILEIRA DE ALIMENTAÇÃO E NUTRIÇÃO, 4., 1996, São Paulo. Anais... São Paulo : SBAN, 1996. NE.36.

TORIN, H.R., DOMENE, S.M.A, FÁRFAN, J.A. Programas emergenciais de combate à fome e o uso de subprodutos de alimentos. Revista de Ciências Médicas-PUCCAMP, Campinas, v.5, n.2, p.87-98, 1996.

VITTI, P., FIGUEIREDO, I.B., ANGELUCCI, E. Folhas de mandioca desidratadas para fins de alimentação humana. Coletânea do Instituto de Tecnologia de Alimentos, Campinas, v.4, p.117-125, 1971.

Recebido para publicação em 28 de junho de 1999 e aceito em 22 de fevereiro de 2000. 